\title{
Auricular Transcutaneous Vagus Nerve Stimulation may Increase the Risk of Mild- COVID-19 Infection or of Herpetic Flare: Is there a Role of Microbiota?
}

\section{Donatini $\mathrm{B}^{*}$ and Le Blaye I}

Medicine Information Formation (Research), Cormontreuil, France

${ }^{*}$ Corresponding author: Donatini B, Gastroenterology-Hepatology, Medicine Information Formation (Research), $40 \mathrm{rue}$ du Dr Roux, 51350 Cormontreuil, France, Tel: 0608584629,E-mail: donatini@orange.fr

Citation: Donatini B, Le Blaye I (2021) Auricular Transcutaneous Vagus Nerve Stimulation may Increase the Risk of Mild-COVID-19 Infection or of Herpetic Flare: Is there a Role of Microbiota? J Case Rep Stud 9(2): 205

Received Date: November 29, 2021 Accepted Date: December 14, 2021 Published Date: December 16, 2021

\begin{abstract}
Background: SARS-CoV-2 can reach the central nervous system through the vagal nerve. Microbiota may favour or prevent viral spread.

Objective: Assess whether auricular transcutaneous vagus nerve stimulation (ATVNS) may favour the occurrence of mild-COVID-19 or the recurrence of herpes simplex type 1.

Methods: All data were collected during routine consultations for Small Intestinal Bowel Overgrowth.

Results: 749 patients were included. 195 patients were recommended and comply with ATVNS. 67 patients of the ATVNS group experienced mild-COVID-19 (34.3\%) versus only 28 in the not-recommended ATVNS group (525 patients; 5.3\%). A similar percentage was observed in the non-compliant ATVNS group (one case for 29 patients; $3.4 \%$ ) [p<0.001].

37 patients of the ATVNS group experienced a labial herpetic flare (19.0\%) versus only 26 in the not-recommended ATVNS group (5.0\%). One labial herpetic flare was observed in the non-compliant ATVNS group $(\mathrm{p}<0.001)$.

Patients who experienced mild-COVID-19 initially present with low levels of hydrogen sulphide and of butyrate in exhaled breath (respectively $0.12+/-0.1$ versus $0.16+/-0.1$ and $0.58+/-0.41$ versus $1.02+/-0.67 \mathrm{ppm}$ ) $(\mathrm{p}<0.001)$. This difference was not observed for herpetic flares.
\end{abstract}

Conclusion: A reduced diversity of microbiota in the foregut may favour the primo-infection with COVID-19. ATVNS may increase the risk of clinical expression of COVID-19 or of herpes labialis.

Keywords: Vagus; COVID-19; Breath test; Microbiota; Herpes

List of abbreviations: ACE2-R: Angiotensin-Converting Enzyme-2 Receptor; ATVNS: Auricular Transcutaneous Vagus Nerve Stimulation; COVID-19: Coronavirus Disease; E-VOCs: Exhaled Volatile Organic compounds; HSV-1: Herpes Simplex Virus type 1; H2S: Hydrogen sulphide; NK: Natural Killer; NO: Nitric Oxide; SIBO: Small Intestinal Bacterial Overgrowth; TH1: T-Helper type 1; VIP: Vasoactive Intestinal Peptide 


\section{Introduction}

\section{SARS-COV-2 spread. The importance of the vagus nerve}

SARS-CoV-2 is a neurotropic virus leading to pleiotropic neurological symptoms [1-4]. Vagus nerves may be involved [5]. The vagal nerve is indeed a classical pathway to access to the central nervous system for herpes viruses [6-9], prions [10,11] or abnormal proteins like alpha-synuclein [12-15] or tau [16]. The vagal autonomic pathway may therefore be at the crossroad of neurotropic viral diseases and tauopathies/prionopathies [17].

\section{SARS-COV-2 and microbiota}

Imbalanced intestinal microbiota may favour chronic inflammation/destruction of mucosa, vagal impairment, as well as decreased immunity [18,19]. Regarding this latter point, gut microbiota may impact on the occurrence of mild Coronavirus Disease (COVID-19) [20]. In particular decreased diversity - illustrated by a low level of butyrate - may increase the risk of COVID-19 [2125]. Modulation of gut microbiota may therefore prevent or decrease the cytokine storm in COVID-19 [26].

\section{Evaluation of the microbiota of the foregut with breath tests}

Intestinal microbiota can be studied by the analysis of exhaled gases [27]. Hydrogen sulphide (H2S) and nitric oxide (NO) are well documented neuroprotective gasotransmitters [28-31]. NO is mainly synthetized by the foregut microbiota [32,33]. Lack of NO and $\mathrm{H} 2 \mathrm{~S}$ production in the stomach may explain gastroduodenal emptying disturbances [34].

\section{Gastroduodenal emptying disturbances}

In animals, gastroduodenal emptying is controlled by the left vagal nerve, by NO and by intramuscular Cajal's cells [35-38]. In humans, delayed gastric emptying is associated with impaired vagal activity [39]. Gastric emptying can be evaluated by transabdominal ultrasound examination [40].

\section{Auricular transcutaneous vagus nerve stimulation (ATVNS) in gastric emptying disturbances}

ATVNS is particularly used to decrease the inflammation in the gut, especially in inflammatory bowel disease [41,42]. In animals, ATVNS appears to be efficacious in gastric emptying disturbances [43-45]. In humans, ATVNS has also been successfully used in gastric emptying disturbances [46] and has been suggested to improve dysautonomia associated with neurodegenerative disease, especially in Parkinson's disease [47].

In this cohort, we recommended such a therapy in patients presenting with gastroduodenal emptying disturbances, evaluated by a transabdominal ultrasound examination.

However, ATVNS was not recommended in patients presenting with jejunal spasm (vagal hypertonia). Jejunal spasm is objectivised in $51.3 \%$ of overweight and in $97.7 \%$ of obesity [48]. In such patients, vagal block (the opposite of ATVNS) should rather be recommended, according to preliminary studies [49-51].

\section{Aim of this descriptive retrospective epidemiological study}

Since the autonomic nervous system may influence positively mucosal inflammation (perhaps microbiota) and negatively the propagation of viruses, we investigated whether auricular transcutaneous vagus nerve stimulation decreased or increased the risk of COVID-19 or of labial herpetic flare. 
We also investigated whether arguments in favour of dysbiosis may influence the benefit or the risk associated with the use of ATVNS.

\section{Material and Methods}

This work is a descriptive retrospective epidemiological study.

Data were collected during the normal course of routine gastroenterological consultations for Small Intestinal Bacterial Overgrowth, from 2020 January 24th (the start of COVID-19 epidemic in France) to 2021 November 15th.

There was no hypothesis testing before data collection, no data collection beyond that which is part of routine clinical practice, no scheduled data analysis before the work has already been done. This retrospective analysis of Case Series cannot therefore be qualified as "research" and does not require approval from ethics boards designed to protect humans involved in clinical research, according to the International Committee of Medical Journal Editors (ICMJE).

\section{Inclusion criteria}

Patients consulting for small intestinal bacterial overgrowth (SIBO) and who underwent a breath test.

Patients should provide with a full medical history, especially regarding ongoing medications, cancer, herpes simplex, herpes zoster, periodontitis, Crohn's disease or ulcerative colitis, depression, thyroid pathologies, auto-immune diseases, allergic reactions, arrhythmia, depression, osteoporosis, body weight and height, as well as diabetes mellitus or any type of organ insufficiency.

Transabdominal ultrasound examination is routinely performed in patients consulting for SIBO. Patients signed a written consent for the possible retrospective use of the collected data.

\section{Exclusion criteria}

More than 70 years of age, ongoing tobacco abuse (which may interfere with E-VOCs); lack of transabdominal ultrasound; lack of signed consent for possible retrospective epidemiological use of data; uncontrolled diabetes mellitus; any uncontrolled organ insufficiency (including pulmonary, renal, cardiac or hepatic insufficiency); any uncontrolled autoimmune or inflammatory disease (including multiple sclerosis, Crohn's disease, ulcerative colitis, rheumatoid arthritis, spondylarthrosis); patients treated with anticancer chemotherapy; lack of breath test or recent intake of antibiotic therapy or of essential oils leading to massive destruction of the digestive flora and less than $2 \mathrm{ppm}$ of E-VOCs at the first measure, after 10 hours of fasting; uncontrolled endocrine disease (including thyroid insufficiency); incomplete data on drug or food complement intake. 44 patients older than 70 years of age were excluded. Except this latter point, only 7 patients were excluded for one of the abovementioned criteria: uncontrolled Crohn's disease (5 patients) or ongoing chemotherapy (2 patients).

All patients vaccinated against COVID-19 were excluded of the study. In France, the vaccination program began on 2020 December $27^{\text {th }} .211$ patients, younger than 70 years of age, were excluded for this reason.

\section{ATVNS}

ATVNS was recommended in patients with gastroduodenal-emptying disturbances and only when jejunal spasm was excluded by an ultrasound examination. Echography objectivised jejunal hypotonia with jejuno-duodenal reflux and dilatation of the first jejunal loops. 
Vagal stimulation is expected to release acetylcholine and therefore to improve bowel movements. Although jejunal spasm is not per se a contra-indication of ATVNS, vagal stimulation does not appear appropriate to improve such a situation.

The patient stimulates the auricular branch of the left vagal nerve with the device "Urostim2" (Schwa-Medico France ). The selected program is $\mathrm{U} 3$. The frequency of stimulation is $10 \mathrm{~Hz}$; pulse duration is $200 \mu \mathrm{s}$, with continuous stimulation for 20 minutes.

The stimulation intensity was set to the individual's tolerance threshold. [42].The stimulation is performed every day, at least during 6 months within the follow-up period. ATVNS should have been initiated after 2020 January $14^{\text {th }}$. The follow-up is performed every 6 months afterwards. Non-observance has been stated when vagus stimulation was performed less than 4 weeks or less than twice a week instead of every day. 195 patients reported full compliance with at least ATVNS 6 days per week for 6 months. 29 patients reported almost complete lack of compliance with premature cessation of ATVNS (within 4 weeks) or only sporadic ATVNS (less than twice per week).

\section{Ultrasound examination}

Gastroparesis was diagnosed when the surface of the stomach reached $10 \mathrm{~cm}^{2}$ after 10 hours of fasting. Ileal distension was diagnosed as soon as ileal diameter reached $2.2 \mathrm{~cm}$ at the ileocecal junction. Lack of gastro-duodenal voiding was diagnosed when no evacuation of bubbles between the superior mesenteric artery and the aorta was observed after 2 minutes of osteopathic abdominal manoeuvers. Jejunal hypotonia could also be implicated. In that case, the jejunum contains few bubbles and no peristalsis is visualized [40]. Abdominal ultrasound examination also enables to diagnose liver steatosis.

\section{Gas measurement}

The patient comes after at least 10 hours of fasting. He /she inhales room air and hold his/her breath for 20 seconds. He/she exhales the air of the lungs in a first neutral plastic bag (1.3 litre) and afterwards he/she exhales at least $100 \mathrm{ml}$ (expected to belong to the expiratory reserve volume) in a small neutral plastic bag (Contralco ; Gignac; France; www.contralco.com).

E-VOCs from the second bag are then immediately measured by the X-pid $9500^{\circ}$, an ambulatory gas chromatograph associated with photoionization detection technology [Dräger; Lubeck; Germany; www.draeger.com > Products > Multi-Gas-Detectors]. X-pid 9500 detects concentrations of volatile organic compounds as low as 50 ppb. Butyric acid is detected between 7.0 and 7.9 seconds.

X-pid $9500^{\circ}$ was used after breath holding and only after fasting, not after sugar intake. X-pid 9500 does not detect H2S.

The air of the first bag is analysed by the Dräger X-am 8000 . We routinely use the Dräger X-am 8000 [Dräger; Lubeck; Germany; www.draeger.com > Products > Multi-Gas-Detectors] to measure H2S.

Both devices are easily portable and equipped with powerful pumps. Patients could be placed in separate rooms when necessary. The setup is basic and similar for both devices. It requires only a short neutral tube to connect the bag and the device.

The results are quantified and directly exported in Excel tables.

\section{Mild-COVID-19 diagnosis}

The diagnosis of COVID-19 was usually made by Polymerase Chain Reaction and reported by the patient him/herself or written on his/her hospital record. It could also have been made by the general practitioner after suggestive symptoms and a serological control.

To be assigned to the ATVNS group, it is necessary that mild-COVID-19 started during the ATVNS period. 


\section{Labial herpetic recurrence}

Herpetic recurrence is reported by the patient. To be assigned to the ATVNS group, it is necessary that the herpetic flare started during the ATVNS period.

\section{Data concerning the different group of patients}

749 patients were included. ATVNS was not-recommended in 525 patients and recommended in 195 patients. 29 patients were not compliant.

Mild-COVID-19 was reported in 96 patients. Labial herpetic recurrence was reported in 64 cases. Mild-COVID and labial herpetic recurrence occurred concomitantly in 14 patients.

\section{Statistics}

Comparisons of percentages or means used two-sample t-tests. Yates correction was used for small samples.

We compared the patients treated with ATVNS with patients not treated with ATVNS.

Since there may be a bias in the selection of patients who were recommended this device, we also compared complying patients with non-complying patients. Because of the large number of tests performed the threshold of statistical significance was set to $\mathrm{p}<0.001$.

\section{Control group}

All consulting patients were pre-included into the study and no case was discarded except when at least one exclusion criteria was identified. As a consequence no recruitment or selection bias is expected.

Two control groups were considered. Patients not recommended with ATVNS or non-compliant patients. In this latter instance, a bias of selection is excluded.

Classical demographic data will be compared. The control groups appear appropriate.

\section{Results}

This descriptive epidemiological study includes 749 ambulatory patients with mild SIBO. No patient presenting with uncontrolled inflammatory or autoimmune disease, as well as uncontrolled organ insufficiency, diabetes, hypertension or endocrine disorders was included. No patients receiving chemotherapy was included. Only patients receiving maintenance drug treatments, food complements or no treatment were therefore included.

Age, body weight and height were similar across groups.

The descriptive demographic data are summarized in Table 1. 195 patients were actually treated (recommended ATVNS and compliant patients) with ATVNS. 29 patients were not compliant and therefore not included into the ATVNS group. 96 patients experienced mild-COVID-19. 64 patients experienced a labial herpetic recurrence (Table 1). 


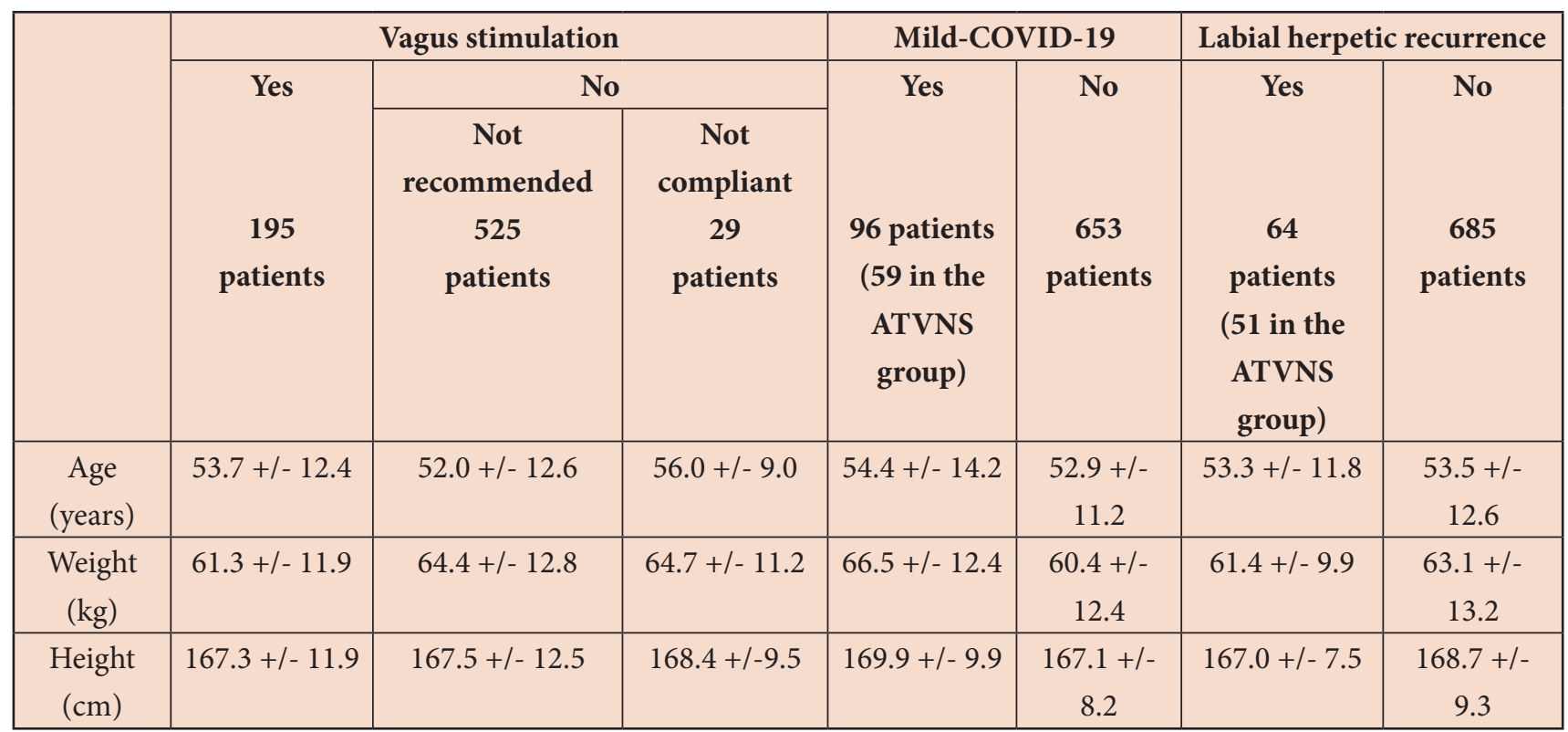

No comparison was statistically significant $(\mathrm{p}>0.001)$

Table 1: Demographic data

67 cases of mild-COVID-19 occurred in the ATVNS group (34.3\%) versus only 1 in the non-compliant group (3.4\%) and 28 in the group of patients where ATVNS was not recommended (5.3\%). The difference was statistically significant $(\mathrm{p}<0.001)$ (Table 2$)$.

37 cases of labial herpes occurred in the ATVNS group (19.0\%) versus one in the non-compliant group (3.4\%) and only 26 in the group of patients where ATVNS was not recommended (5.0\%). The difference was also statistically significant $(\mathrm{p}<0.001)$ (Table 2$)$. To be assigned to the ATVNS group, it is necessary that mild-COVID-19 or herpes recurrence started during the ATVNS period.

\begin{tabular}{|c|c|c|c|}
\hline & \multicolumn{3}{|c|}{ Vagus stimulation } \\
\hline & Yes & \multicolumn{2}{|c|}{ No } \\
\hline & 195 patients & $\begin{array}{l}\text { Not recommended } \\
525 \text { patients }\end{array}$ & $\begin{array}{c}\text { Not compliant } \\
29 \text { patients }\end{array}$ \\
\hline $\begin{array}{l}\text { Hydrogen sulphide } \\
\text { ppm }\end{array}$ & $0.13+/-0.07$ & $0.15+/-0.11$ & $0.13+/-0.08$ \\
\hline $\begin{array}{c}\text { Butyrate } \\
\text { ppm }\end{array}$ & $0.78+/-0.49$ & $0.85+/-0.69$ & $1.03+/-0.44$ \\
\hline Mild-COVID-19 & $67(34.3 \%)^{*}, \S$ & $28(5.3 \%)^{\star}$ & $1(3.4 \%) \S$ \\
\hline Labial herpetic recurrence & $37(19.0 \%)^{\star *}, \dagger$ & $26(5.0 \%)^{* *}$ & $1(3.4 \%) \dagger$ \\
\hline $\begin{array}{l}\text { Simultaneous Mild-COVID-19 } \\
\text { and labial herpetic recurrence }\end{array}$ & $11(5.6 \%)^{\star * *}$ & $3(0.6 \%)^{\star * *}$ & $0(0 \%)$ \\
\hline $\begin{array}{l}\text { Previous labial herpetic } \\
\text { recurrence within the } 6 \text { previous } \\
\text { months }\end{array}$ & $9(4.6 \%)$ & $28(5.3 \%)$ & $2(6.9 \%)$ \\
\hline
\end{tabular}

Table 2: Results of breath tests and occurrence of mild-COVID-19 or labial herpetic flare in patients treated with ATVNS or not (either not-recommended ATVNS or non-compliant patients) 
Mild-COVID-19 and labial herpetic recurrence occurred simultaneously in 14 patients: 11 in the ATVNS group (5.6\%) and 3 in the not-recommended ATVNS group (0.6\%) [p<0.001].

However, in most cases, the occurrence of the two infections was not concomitant.

Previous labial herpetic recurrence was not more frequently reported in the ATVNS group than in the not-recommended ATVNS group (4.6\% versus 5.3\%; $\mathrm{p}>0.05)$.

The level of H2S or of butyrate - after fasting and before ATVNS was initiated - was similar in the ATVNS group, in the notrecommended ATVNS group and in the non-compliant group.

The level of H2S or of butyrate was lower in patients who subsequently experienced mild-COVID-19: respectively $0.12+/-0.10$ versus $0.16+/-0.10$ and $0.58+/-0.41$ and $1.02+/-0.67 \mathrm{ppm}(\mathrm{p}<0.001)$ (Table 3$)$.

\begin{tabular}{|c|c|c|c|c|}
\hline \multirow{2}{*}{} & \multicolumn{2}{|c|}{ Mild-COVID-19 } & \multicolumn{2}{c|}{ Labial herpetic flare } \\
\cline { 2 - 5 } & $\begin{array}{c}\text { Yes } \\
\mathbf{9 6} \text { patients }\end{array}$ & $\begin{array}{c}\text { No } \\
\mathbf{6 5 3} \text { patients }\end{array}$ & $\begin{array}{c}\text { Yes } \\
\mathbf{6 4} \text { patients }\end{array}$ & $\begin{array}{c}\text { No } \\
\text { patients }\end{array}$ \\
\hline $\begin{array}{c}\text { Hydrogen sulphide } \\
\text { ppm }\end{array}$ & $\mathbf{0 . 1 2 ^ { * } + / - \mathbf { 0 . 1 0 }}$ & $\mathbf{0 . 1 6 ^ { * } + / - \mathbf { 0 . 1 0 }}$ & $0.13+/-0.08$ & $0.14+/-0.11$ \\
\hline $\begin{array}{c}\text { Butyrate } \\
\text { ppm }\end{array}$ & $\mathbf{0 . 5 8} \$+/-\mathbf{0 . 4 1}$ & $\mathbf{1 . 0 2} \$+/-\mathbf{0 . 6 7}$ & $0.70+/-0.53$ & $0.85+/-0.62$ \\
\hline \multicolumn{2}{|c|}{${ }^{*} \mathrm{p}<0.001 ; \$ p<0.001$} & \\
\hline
\end{tabular}

Table 3: Results of breath tests according to mild-COVID-19 or to labial herpetic flare

The level of H2S or of butyrate was not different between patients who experienced herpetic flares and those who did not.

The level of $\mathrm{H} 2 \mathrm{~S}$ was lower in patients who subsequently experienced mild-COVID-19: respectively $0.11+/-0.06$ versus $0.15+/-0.07$ in patients treated with ATVNS and $0.12+/-0.10$ and $0.17+/-0.08 \mathrm{ppm}(\mathrm{p}<0.001)$ in patients who were not recommended ATVNS (Table 4).

The level of butyrate was also lower in patients who subsequently experienced mild-COVID-19: respectively $0.58+/-0.41$ versus 0.82 $+/-0.51$ in patients treated with ATVNS and $0.50+/-0.27$ and $0.1 .19+/-0.73 \mathrm{ppm}(\mathrm{p}<0.001)$ in patients who were not recommended ATVNS.

The results of the non-compliant patients without mild-COVID-19 were similar to those of the not-recommended ATVNS group without mild-COVID-19 (Table 4). 


\begin{tabular}{|c|c|c|c|c|c|c|}
\hline & \multicolumn{3}{|c|}{$\begin{array}{l}\text { Mild-COVID-19 } \\
\qquad 96 \text { cases }\end{array}$} & \multicolumn{3}{|c|}{$\begin{array}{l}\text { Lack of diagnosis of mild-COVID-19 } \\
6653 \text { patients }\end{array}$} \\
\hline & $\begin{array}{l}\text { ATVNS } \\
67 \text { cases }\end{array}$ & $\begin{array}{c}\text { Not- } \\
\text { recommended } \\
\text { ATVNS } \\
28 \text { cases }\end{array}$ & $\begin{array}{c}\text { Non-compliant } \\
\text { patient } \\
1 \text { case }\end{array}$ & $\begin{array}{c}\text { ATVNS } \\
128 \text { patients }\end{array}$ & $\begin{array}{c}\text { Not- } \\
\text { recommended } \\
\text { ATVNS } \\
497 \text { patients }\end{array}$ & $\begin{array}{c}\text { Non- } \\
\text { compliant } \\
\text { patients } \\
28 \text { patients }\end{array}$ \\
\hline $\begin{array}{l}\text { Hydrogen } \\
\text { sulphide } \\
\text { ppm }\end{array}$ & $0.11+/-0.06^{*}$ & $0.12+/-0.15 \S$ & 0.06 & $0.15+/-0.07^{\star}$ & $0.17+/-0.08 \S$ & $0.13+/-0.08$ \\
\hline $\begin{array}{l}\text { Butyrate } \\
\text { ppm }\end{array}$ & $0.58+/-0.41^{\star}$ & $0.50+/-0.27 \S$ & 0.70 & $0.82+/-0.51^{*}$ & $1.19+/-0.73 \S$ & $1.04+/-0.44$ \\
\hline
\end{tabular}

${ }^{*} \mathrm{p}<0.001 ; \S \mathrm{p}<0.001$

Table 4: Results of breath tests is patients treated with ATVNS or not (either not-recommended ATVNS or noncompliant patients) according to the occurrence of mild-COVID-19

\section{Discussion}

Primo-infection (mild-COVID-19) and recurrence labial herpes associated with ATVNS are probably not explainable by the same pathogeny, which may explain that in most instances, the occurrence of the two infections was not concomitant.

\section{Primo-infection of COVID-19 and microglia}

Many factors favour the occurrence of symptomatic COVID-19, especially aging, diabetes, heart disease or obesity [52-55]. All these clinical conditions are associated with microglial inflammation (microglial type 1 status) [56,57].

SARS-CoV-2 enters the cells through the angiotensin-converting enzyme-2 receptors (ACE2-R). The expression of ACE2-R is markedly upregulated on activated type 1 macrophages such as alveolar macrophages, Kupffer cells within liver, and microglial cells in brain [58-60]. Microglial cells are known to participate to the transport of SARS-CoV-2 to the brain [61]. They are considered as a reservoir of SARS-CoV-2. They do not control the replication of the virus and additionally favour severe inflammation and therefore cytokine storm [61].

White visceral adipose tissue, increased in individuals with obesity, is also a viral reservoir for SARS-CoV-2 via an increased expression of ACE2-R [62]. Finally the number of ACE2-R is incremented by aging [63].

Aging may also change gut microbiota and decrease immune protection [64]. However, we did not find any difference regarding breath tests results between groups and included patients have only mild comorbidities. There is no argument in favour of any discrepancy between the immunological status or gut intestinal diversity between the patients treated with ATVNS and those not treated with ATVNS, especially regarding the non-observant ATVNS group.

Regarding the patients who were not recommended ATVNS and who rarely experienced mild-COVID-19 in comparison with the ATVNS-treated group, one can argue that gastroduodenal emptying disturbance and therefore pre-existing alteration of the autonomic nerve function may interfere with the number of ACE2-R, immune status or microbiota.

Indeed, leaky gut syndrome is expected to be more frequent in case of dysbiosis and therefore in case of gastroduodenal emptying disturbances. 
Patients with digestive vagal ou myenteric hypotonia may have inflammatory microglial cells in contact with neuronal endings. Naïve microglial cells are surrounding submucosal intraganglionic laminar endings and can be contaminated by SARS-CoV-2 which succeeded to cross the mucosa [64]. Microglial cells are known to be mobile and to join the nodose ganglion [65].

\section{ATVPS increases vasoactive intestinal peptide (VIP) release}

According to animal-related studies, parasympathetic neuronal endings contain VIP [66,67]. These findings were confirmed in immunohistochemical studies performed on human tissues [68,69]. Stimulation of the vagus nerve (10 Hertz) is expected to increases the release of VIP [70] in rats.

In a quiescently infected human cell model of neural stem cells, VIP enhances the proliferation of the cytomegalovirus (which is classified as a herpes virus) [71]. In a murine transplant model, VIP inhibition protects from lethal murine CMV infection [72].

However, VIP is considered as the most prominent immunoregulatory neuropeptide that participates in local tissue immune responses by potently affecting $\mathrm{T}$ cell and macrophage migration, proliferation, and cytokine production [73].

VIP could be able to inhibit the SARS-CoV-2 virus gene replication in human lung epithelial cells, to induce cytoprotective effects, to promote monocyte production, and to increase transmission of viral resistance from monocytes to neighbouring lung cells [74].

VIP decreases microglial induced inflammation by switching the microglial inflammatory M1 pattern to the microglial regulatory M2 pattern [75-77].

ATVNS is therefore unlikely responsible of increased viral replication or of VIP-induced inflammation especially as far as MildCOVID-19 is concerned.

\section{ATVNS is not expected to increase inflammation or to decrease immunity}

In animal models and according to potential therapeutic implications in humans, ATVNS is expected to decrease inflammation [7880].

In humans, calprotectin (a local marker of inflammation) is increased in stools of patients with mild-COVID-19 and diarrhoea [81]. ATVNS is expected to decrease faecal calprotectin levels in Crohn's disease [42].

Increased local inflammation by ATVNS is therefore unlikely.

However, in animal-related studies, specific combinations of parameters of ATVNS produce significant increases in serum TNF while other parameters selectively lowered serum TNF levels [82-83]. Optimal stimulation parameters to control inflammation remain therefore to be determined.

\section{The role of low diversity of microbiota regarding contamination}

The diversity of the oral or of the gut microbiome is decreased in COVID-19 patients and may be correlated with the severity of disease [21-25]. High levels of short-chain fatty acids may prevent cytokine storm [22].

Butyrate decreases the expression and the activation of Toll-like-receptor 4 and therefore reduces gastrointestinal inflammation in model animals [84]. 
H2S may block SARS-CoV-2 entry into host cells by interfering with ACE2-R and transmembrane protease serine 2, may inhibit SARS-CoV-2 replication by attenuating virus assembly/release, and may protect SARS-CoV-2-induced lung damage by suppressing immune response and inflammation development $[85,86]$.

The age-dependent decline of the extracellular thiol-disulphide balance may explain the increased risk of COVID-19 in aged patients [87].

Decreased availability of nitric oxide and hydrogen sulphide could be a hallmark of COVID-19 [88,89].

Preclinical studies and clinical trials with slow-releasing H2S donor(s) or the activators of endogenous H2S-generating enzymes are considered as a preventative treatment or therapy for COVID-19 [90-95].

In this retrospective epidemiological cohort, exhaled hydrogen sulphide and butyrate levels were similar in patients selected for ATVNS and those not-selected for ATVNS. We can therefore conclude that impairment of gastroduodenal emptying does not modify the concentration of these gases as far as exhaled air is concerned. In contrast, we demonstrated in a previous study that NO and $\mathrm{H} 2 \mathrm{~S}$ levels were modified in gastric air which was obtained after belching; not in exhaled air [34].

$\mathrm{H} 2 \mathrm{~S}$ and butyrate levels were lower in patients who experienced mild-COVID-19 either treated or not with ATVNS.

This latter point speaks in favour of a strong protective influence of a diversified microbiota against contamination with SARSCoV-2.

The underlying condition (namely altered gastroduodenal emptying) per se does not appear to influence the occurrence of symptoms of COVID-19.

Eventually, ATVNS may only increase the spread of microglial cells, mild inflammation and therefore the frequency of screening that will end to mild-COVID-19 diagnosis. ATVNS likely does not trigger contamination.

\section{ATVNS and autophagy}

SARS-CoV-2 exploits similar components of the autophagy machinery to create their replication organelles [96-98].

Autophagy, through the cleaning of inflammatory bacteria or fungi, controls the quality of the gut microbiota [99]. Consequently impaired autophagy increases inflammation and triggers excessive apoptosis [100]. A positive feedback by small chain fatty acids attenuates autophagy and relieves inflammation in a colitis mice-model [101].

Vagal nerve stimulation inhibits excessive autophagy and apoptosis in a rat-model of cerebral ischemia-reperfusion injury [102].

ATVNS is expected to decrease autophagy and therefore not to increase the replication of SARS-CoV-2.

\section{Recurrence of herpes simplex}

After the primo-infection, HSV-1 gains access to the termini of local sensory neurons (most commonly the trigeminal ganglion) by a retrograde axonal transport. Herpes simplex virus type 1 (HSV-1) persist in trigeminal ganglia neuronal nuclei as chromatinized episomes. Fluctuations in anti-viral immunological status underlay periodic reactivations. Innate immunity is the first line of defence against HSV-1 infection, especially macrophages, $\gamma \delta$ T-cells, NK cells and type 1 interferons [103]. 
In latently HSV-1-infection, the main part of the leukocyte infiltrate consists of HSV1-specific a $\beta$ T-cells, some macrophages [104] and satellite glial cells [105]. Glial cells appear to orchestrate the immune control and play the pivotal role [106].

Dysbiosis could play some role in the reactivation of HSV-1. Butyrate increases the replication of HSV-1, up to 2000 times [107], leading the HSV-1 reactivation in the trigeminal nerve $[108,109]$ according to human-cells or animal-models.

HSV1 favours inappropriate autophagy and therefore its spread [110-112].

In mice-models, NO possesses major anti-HSV1 properties [113,114]. HSV-1 is therefore more present in neurons poor in NO [115] and manages to decrease NO levels which enable its reactivation [116].

In this cohort, herpes reactivation was not associated with altered H2S (involved in the synthesis of NO) or butyrate level.

Reactivation of HSV-1 infection could rather be related to mobilisation of immune cells localised in the trigeminal ganglia, especially microglial cells.

\section{Global hypothesis}

ATVNS favours the spread of neurotropic viruses into autonomic nervous system and eventually into central nervous system leading to symptomatic COVID-19. It also increases the risk of recurrence of labial herpetic flare.

ATVNS does probably not alter autophagy, mucosa permeability or microbiota diversity.

ATVNS may favour the circulation of microglial cells to their targets: the central nervous system for viral primo-infections such as SARS-CoV-2 or the periphery for HSV-1.

Regarding COVID-19, the infected microglial cells start from the submucosal intraganglionic laminar endings of the nasal/oral/ pulmonary or digestive mucosa and follow the afferent pathway of the vagus, joint the bipolar nodose ganglion and spread to all organs.

Regarding HSV-1, the infected microglial cells start from the trigeminal ganglion and follow the sensory nerve in an anterograde direction.

Inflammatory microglial cells - perhaps presenting with increased ACE2-receptors - are more numerous in case of low microbiota diversity and low butyrate level.

Symptoms of primo-infection may therefore require the synergic effect of low diversity (low H2S level and low butyrate level) and of ATVNS.

The diversity of microbiota appears as a cornerstone of the protection against COVID-19.

\section{Limitations of the study}

It is a retrospective epidemiological study with a large diversity of therapies and behaviours. However, the population included was quite homogeneous because of restrictive inclusion and exclusion criteria (less than 70 years of age, no immunosuppressive therapy, no uncontrolled autoimmune or inflammatory disease, no uncontrolled diabetes mellitus, no organ failure: cardiac, renal, hepatic, 
respiratory, etc.). Compliant and non-compliant groups regarding demographic date were similar. However, three biases can be evoked.

Firstly, the patients who were recommended ATVNS present with vagal or myenteric hypotonia and an inappropriate gastroduodenal emptying at ultrasound examination.

In such instances, the level of $\mathrm{NO}$ and $\mathrm{H} 2 \mathrm{~S}$ and of butyrate might have been low. It could therefore be objected that the patients recommended to follow ATVNS could have been more prone to develop mild-COVID-19. However, non-compliant patients have a similar microbiota than other patients.

Secondly, some patients of the non-compliant group may have partially performed ATVNS. Such a situation will decrease the difference between the two groups. In this case, the bias tends to misleadingly narrow the differences between the two groups. It therefore suggests an even stronger effect of ATVNS and consequently does not invalidate the findings.

Thirdly, some patients with altered gastroduodenal emptying may have not been diagnosed, may have not been proposed ATVNS or may have refused the treatment when suggested. As a consequence the ATVNS group and the non-ATVNS group are probably more similar than expected. This fact speaks again in favour of an effect related to ATVNS it-self rather than to health status discrepancies between the two groups.

Other well identified risk factors (e.g. diabetes, overweight, age) were not taken into consideration. However, mean age and body weight were similar in all groups and other patients present with underlying mild or controlled diseases. Please remember that these patients were ambulatory patients coming for SIBO.

There is no argument to support any unbalance between groups, except inappropriate gastroduodenal emptying which was the origin of ATVNS prescription.

\section{Application of this new knowledge for routine practice}

ATVNS may favour the occurrence mild-COVID-19 and recurrence of labial herpes simplex. Low levels of H2S or of butyric in exhaled-breath may indicate an increased risk of primo-infection with SARS-CoV2. This risk may also apply to other neurotropic viruses.

We recommend that ATVNS should be prescribed only after adequate vaccination against COVID-19.

The patients should be aware of an increased risk of herpetic flares when ATVNS is used. They should be then suggested to discontinue the device or to receive the appropriate antiviral agent as long as the treatment is pursued.

Breath test may detect slight decrease in hydrogen sulphide or butyrate. A physician should select only patients with H2S levels above 0.15 and with butyrate levels above 0.82 before considering their eligibility for ATVNS.

A control at 6 months should be planned to check for the lack of new microbiota disturbance (for example due to antibiotic therapy), or the occurrence of a herpetic flare, of a mild-COVID-19 or of any viral disease.

Physicians should also keep in mind that prion disease and tauopathies may be based on a similar mechanism. ATVNS should not be used in routine practice in patients who may present with such diseases before the situation has been clarified. 


\section{Conclusion}

ATVNS may increase the risk of primo-infection of COVID-19 and of recurrence of labial herpes simplex. The mechanism has to be further investigated. The diversity of the microbiota seems essential to protect against COVID-19.

Low levels of $\mathrm{H} 2 \mathrm{~S}$ or of butyric in exhaled-breath may indicate an increased risk of primo-infection with SARS-CoV2. This risk may also apply to other neurotropic viruses or particles.

Since ATVNS is more and more prescribed in routine practice in non-severe disease, physician should be aware of such potential complications and put them into perspective with the expected benefits.

The risks should be explained to patients so that they can give an adequate informed consent before they use ATVNS. They will then be able to stop treatment as soon as relevant adverse symptoms appear.

\section{Acknowledgment(S) and Conflicts Of Interest}

No conflict of interest to disclose. 


\section{References}

1. Mao L, Jin H, Wang M, Hu Y, Chen S, et al. (2020) Neurologic Manifestations of Hospitalized Patients With Coronavirus Disease 2019 in Wuhan, China. JAMA Neurol 77: 683.

2. Baig AM (2020) Neurological manifestations in COVID-19 caused by SARS-CoV-2. CNS Neurosci Ther 26: 499-501.

3. Moriguchi T, Harii N, Goto J, Harada D, Sugawara H, et al. (2020) A first case of meningitis/encephalitis associated with SARS-Coronavirus-2. Int J Infect Dis 94: 55-8.

4. Carod-Artal FJ (2020) Neurological complications of coronavirus and COVID-19. Rev Neurol 70: 311-22.

5. Moyano A JR, Mejía Torres S, Espinosa J (2021) Vagus nerve neuropathy related to SARS COV-2 infection. IDCases $26:$ e01242.

6. Li D, Yang H, Xiong F, Xu X, Zeng WB, et al. (2020) Anterograde Neuronal Circuit Tracers Derived from Herpes Simplex Virus

1: Development, Application, and Perspectives. Int J Mol Sci 21: 5937.

7. Tsau PW, Liao MF, Hsu JL, Hsu HC, Peng CH, et al. (2020) Clinical Presentations and Outcome Studies of Cranial Nerve Involvement in Herpes Zoster Infection: A Retrospective Single-Center Analysis. J Clin Med 9: 946.

8. Wang Z, Lotina T, Malaty J (2021) Uncommon presentation and complications of herpes zoster infection involving the cervical, vagus and accessory nerves which caused a delay in diagnosis and treatment. BMJ Case Rep 14: e241881.

9. Nakagawa H, Kusuyama T, Miyamoto M, Saito K, Ikeda S (2021) Primary herpetic oropharyngitis in adults: Differences in clinical features between Herpes simplex virus type 1 and type 2. A retrospective study. Clin Otolaryngol: 10.1111/coa.13888.

10. Davies GA, Bryant AR, Reynolds JD, Jirik FR, Sharkey KA (2006) Prion diseases and the gastrointestinal tract. Can J Gastroenterol 20: 18-24.

11. Kresl P, Rahimi J, Gelpi E, Aldecoa I, Ricken G, et al. (2019) Accumulation of prion protein in the vagus nerve in creutzfeldt-jakob disease. Ann Neurol 85: 782-7.

12. Beekes M (2021) The Neural Gut-Brain Axis of Pathological Protein Aggregation in Parkinson's Disease and Its Counterpart in Peroral Prion Infections. Viruses 13: 1394.

13. Del Tredici K, Braak H (2016) Review: Sporadic Parkinson's disease: development and distribution of $\alpha$-synuclein pathology. Neuropathol Appl Neurobiol 42: 33-50.

14. Dogra N, Mani RJ, Katare DP (2021) The Gut-Brain Axis: Two Ways Signaling in Parkinson's Disease. Cell Mol Neurobiol 10.1007/s10571-021-01066-7.

15. Kim S, Kwon SH, Kam TI, Panicker N, Karuppagounder SS, et al. (2019) Transneuronal Propagation of Pathologic a-Synuclein from the Gut to the Brain Models Parkinson's Disease. Neuron 103: 627-641.e7.

16. Sun Y, Sommerville NR, Liu JYH, Ngan MP, Poon D, et al. (2020) Intra-gastrointestinal amyloid- $\beta 1$-42 oligomers perturb enteric function and induce Alzheimer's disease pathology. J Physiol 598: 4209-23. 
17. Rangon CM, Krantic S, Moyse E, Fougère B (2020) The Vagal Autonomic Pathway of COVID-19 at the Crossroad of Alzheimer's Disease and Aging: A Review of Knowledge. J Alzheimers Dis Rep 4: 537-51.

18. Bonaz B, Bazin T, Pellissier S (2018) The Vagus Nerve at the Interface of the Microbiota-Gut-Brain Axis. Front Neurosci 7: 49.

19. Yoo JY, Groer M, Dutra SVO, Sarkar A, McSkimming DI (2020) Gut Microbiota and Immune System Interactions. Microorganisms 8: 1587.

20. Donatini B, Le Blaye I (2020) Volatile Organic Compounds Associated with Mild COVID-19. Annal Cas Rep Rev ACRR-167.

21. Gao M, Wang H, Luo H, Sun Y, Wang L, et al. (2021) Characterization of the Human Oropharyngeal Microbiomes in SARSCoV-2 Infection and Recovery Patients. Adv Sci (Weinh) 8: e2102785.

22. Jardou M, Lawson R (2021) Supportive therapy during COVID-19: The proposed mechanism of short-chain fatty acids to prevent cytokine storm and multi-organ failure. Med Hypotheses 154: 110661.

23. Li S, Yang S, Zhou Y, Disoma C, Dong Z, et al. (2021) Microbiome Profiling Using Shotgun Metagenomic Sequencing Identified Unique Microorganisms in COVID-19 Patients With Altered Gut Microbiota. Front Microbiol 12: 712081.

24. Xia S, Luo X (2021) Analysis of 2D nanomaterial BC3 for COVID-19 biomarker ethyl butyrate sensor. J Mater Chem B 9: 9221-9229.

25. Moreira-Rosário A, Marques C, Pinheiro H, Araújo JR, Ribeiro P, et al. (2021). Gut Microbiota Diversity and C-Reactive Protein Are Predictors of Disease Severity in COVID-19 Patients. Front Microbiol 12: 705020.

26. Chen J, Vitetta L (2021) Modulation of Gut Microbiota for the Prevention and Treatment of COVID-19. J Clin Med 10: 2903.

27. Donatini B (2015) Bacterial overgrowth of the small intestine. Interest of the hydrogen and methane breath test after lactulose [Pullulation bactérienne de l'intestin grêle. Intérêt du test respiratoire à l'hydrogène et au méthane après lactulose]. Revue Inist Hegel 5: 92-9.

28. Xue X, Bian JS (2015) Neuroprotective effects of hydrogen sulfide in Parkinson's disease animal models: methods and protocols. Methods Enzymol 554: 169-86.

29. Shefa U, Yeo SG, Kim MS, Song IO, Jung J, et al. (2017) Role of Gasotransmitters in Oxidative Stresses, Neuroinflammation, and Neuronal Repair. Biomed Res Int 2017: 1689341.

30. Farrugia G, Szurszewski JH (2014) Carbon monoxide, hydrogen sulfide, and nitric oxide as signaling molecules in the gastrointestinal tract. Gastroenterology 147: 303-13.

31. Kimura H (2020) Hydrogen sulfide signalling in the CNS - Comparison with NO. Br J Pharmacol 177: 5031-45.

32. Hezel MP, Weitzberg E (2015) The oral microbiome and nitric oxide homoeostasis. Oral Dis 21: 7-16.

33. Koch CD, Gladwin MT, Freeman BA, Lundberg JO, Weitzberg E, et al (2017) Enterosalivary nitrate metabolism and the microbiome: Intersection of microbial metabolism, nitric oxide and diet in cardiac and pulmonary vascular health. Free Radic Biol Med 105: 48-67. 
34. Donatini B, Le Blaye I (2021) Levels of Hydrogen Sulphide or Nitric Oxide in induced belching are indicators of adequate gastric voiding. J Clin Case Stu 6: 10.16966/2471-4925.216.

35. Sivarao DV, Mashimo H, Goyal RK (2008) Pyloric sphincter dysfunction in nNOS-/- and W/Wv mutant mice: animal models of gastroparesis and duodenogastric reflux. Gastroenterology 135: 1258-66.

36. Anselmi L, Toti L, Bove C, Travagli RA (2017) Vagally mediated effects of brain stem dopamine on gastric tone and phasic contractions of the rat. Am J Physiol Gastrointest Liver Physiol 313: G434-G441.

37. Beckett EA, Sanders KM, Ward SM (2017) Inhibitory responses mediated by vagal nerve stimulation are diminished in stomachs of mice with reduced intramuscular interstitial cells of Cajal. Sci Rep 7: 44759.

38. Sevgili AM, Balkanci DZ, Erdem A (2017). Potential excitatory role of nitric oxide on 2-deoxy-d-glucose-induced gastric motility in rats. Clin Exp Pharmacol Physiol 44: 693-9.

39. Guo WJ, Yao SK, Zhang YL, Du SY, Wang HF, et al (2018). Impaired vagal activity to meal in patients with functional dyspepsia and delayed gastric emptying. J Int Med Res 46: 792-801.

40. Donatini B (2019) Interest of abdominal ultrasound for the analysis of emptying, reflux and gastro-duodeno-jejuno-ileal tone [Intérêt de l'échographie abdominale pour l'analyse des vidanges, des reflux et de la tonicité gastro-duodéno-jéjuno-iléale]. Hegel 9: $1-7$.

41. Marshall R, Taylor I, Lahr C, Abell TL, Espinoza I, et al. (2015) Bioelectrical Stimulation for the Reduction of Inflammation in Inflammatory Bowel Disease. Clin Med Insights Gastroenterol 8: 55-9.

42. Yap JYY, Keatch C, Lambert E, Woods W, Stoddart PR, et al. (2020) Critical Review of Transcutaneous Vagus Nerve Stimulation: Challenges for Translation to Clinical Practice. Front Neurosci 14: 284.

43. Zhang Y, Lu T, Dong Y, Chen Y, Chen JDZ (2021) Auricular vagal nerve stimulation enhances gastrointestinal motility and improves interstitial cells of Cajal in rats treated with loperamide. Neurogastroenterol Motil 33: e14163.

44. Li H, Yin J, Zhang Z, Winston JH, Shi XZ, et al. (2016) Auricular vagal nerve stimulation ameliorates burn-induced gastric dysmotility via sympathetic-COX-2 pathways in rats. Neurogastroenterol Motil 28: 36-42.

45. Li H, Zhang JB, Xu C, Tang QQ, Shen WX, et al. (2015) Effects and mechanisms of auricular vagus nerve stimulation on highfat-diet--induced obese rats. Nutrition 31: 1416-22.

46. Zhu Y, Xu F, Lu D, Rong P, Cheng J, et al. Transcutaneous auricular vagal nerve stimulation improves functional dyspepsia by enhancing vagal efferent activity. Am J Physiol Gastrointest Liver Physiol 320: G700-G711.

47. Ko DWK (2021) Transcutaneous vagus nerve stimulation (tVNS) as a potential therapeutic application for neurodegenerative disorders - A focus on dysautonomia in Parkinson's disease. Auton Neurosci 235: 102858.

48. Donatini B, Le Blaye I (2021) Weight loss associated with maitake or tiny amounts of essential oils. Annals of Case Reports and Reviews 10.39127/2574/5747/ACRR:246.

49. De Lartigue G (2016) Role of the vagus nerve in the development and treatment of diet-induced obesity. J Physiol 594: $5791-815$. 
50. Apovian CM, Shah SN, Wolfe BM, Ikramuddin S, Miller CJ, et al. (2017) Two-Year Outcomes of Vagal Nerve Blocking (vBloc) for the Treatment of Obesity in the ReCharge Trial. Obes Surg 27: 169-76.

51. Berthoud HR, Neuhuber WL (2019) Vagal mechanisms as neuromodulatory targets for the treatment of metabolic disease. Ann N Y Acad Sci 1454: 42-55.

52. Rea IM, Alexander HD (2021) Triple Jeopardy in Ageing: COVID-19, Co-morbidities and Inflamm-ageing. Ageing Res Rev 73: 101494.

53. Manolis AS, Manolis AA, Manolis TA, Apostolaki NE, Melita H (2021) COVID-19 infection and body weight: A deleterious liaison in a J-curve relationship. Obes Res Clin Pract 15: 523-35.

54. Steenblock C, Schwarz PEH, Ludwig B, Linkermann A, Zimmet P, et al. (2021) COVID-19 and metabolic disease: mechanisms and clinical management. Lancet Diabetes Endocrinol 9: 786-98.

55. Magdy Beshbishy A, Oti VB, Hussein DE, Rehan IF, Adeyemi OS, et al. (2021) Factors Behind the Higher COVID-19 Risk in Diabetes: A Critical Review. Front Public Health 9: 591982.

56. Russo S, Kwiatkowski M, Govorukhina N, Bischoff R, Melgert BN (2021) Meta-Inflammation and Metabolic Reprogramming of Macrophages in Diabetes and Obesity: The Importance of Metabolites. Front Immunol 12:746151. doi: 10.3389/fimmu.2021.746151.

57. Appari M, Channon KM, McNeill E (2018) Metabolic Regulation of Adipose Tissue Macrophage Function in Obesity and Diabetes. Antioxid Redox Signal 29: 297-312.

58. Song X, Hu W, Yu H, Zhao L, Zhao Y, et al. (2020) Little to no expression of angiotensin-converting enzyme-2 on most human peripheral blood immune cells but highly expressed on tissue macrophages. Cytometry A 10.1002/cyto.a.24285.

59. Torices S, Cabrera R, Stangis M, Naranjo O, Fattakhov N, et al. (2021) Expression of SARS-CoV-2-related receptors in cells of the neurovascular unit: implications for HIV-1 infection. J Neuroinflammation 18: 167.

60. Olivarria GM, Cheng Y, Furman S, Pachow C, Hohsfield LA, et al. (2021) Microglia do not restrict SARS-CoV-2 replication following infection of the central nervous system of K18-hACE2 transgenic mice. bioRxiv: 10.1101/2021.11.15.468761.

61. Jakhmola S, Indari O, Chatterjee S, Jha HC (2020) SARS-CoV-2, an Underestimated Pathogen of the Nervous System. SN Compr Clin Med 28: 1-10.

62. Lasbleiz A, Gaborit B, Soghomonian A, Bartoli A, Ancel P, et al. COVID-19 and Obesity: Role of Ectopic Visceral and Epicardial Adipose Tissues in Myocardial Injury. Front Endocrinol (Lausanne) 12: 726967.

63. Farshbafnadi M, Kamali Zonouzi S, Sabahi M, Dolatshahi M, Aarabi MH (2021) Aging \& COVID-19 susceptibility, disease severity, and clinical outcomes: The role of entangled risk factors. Exp Gerontol 154: 111507.

64. Hussain I, Cher GLY, Abid MA, Abid MB (2021) Role of Gut Microbiome in COVID-19: An Insight Into Pathogenesis and Therapeutic Potential. Front Immunol 12: 765965.

65. Smolders SM, Kessels S, Vangansewinkel T, Rigo JM, Legendre P, et al. (2019) Microglia: Brain cells on the move. Prog Neurobiol 178: 101612 . 
66. Zhou SY, Lu YX, Yao H, Owyang C (2008) Spatial organization of neurons in the dorsal motor nucleus of the vagus synapsing with intragastric cholinergic and nitric oxide/VIP neurons in the rat. Am J Physiol Gastrointest Liver Physiol 294: G1201-9.

67. Markos F, Snow HM (2006) Vagal postganglionic origin of vasoactive intestinal polypeptide (VIP) mediating the vagal tachycardia. Eur J Appl Physiol 98: 419-22.

68. Lundberg M, Lindqvist A, Wierup N, Krogvold L, Dahl-Jørgensen K, et al. (2017) The density of parasympathetic axons is reduced in the exocrine pancreas of individuals recently diagnosed with type 1 diabetes. PLoS One 12: e0179911.

69. Hinata N, Hieda K, Sasaki H, Murakami G, Abe S, et al. (2014) Topohistology of sympathetic and parasympathetic nerve fibers in branches of the pelvic plexus: an immunohistochemical study using donated elderly cadavers. Anat Cell Biol 47: 55-65.

70. Bockx I, Verdrengh K, Vander Elst I, van Pelt J, Nevens F, et al. (2012) High-frequency vagus nerve stimulation improves portal hypertension in cirrhotic rats. Gut 61: 604-12.

71. Yuan J, Li M, Torres YR, Galle CS, Meier JL (2015) Differentiation-Coupled Induction of Human Cytomegalovirus Replication

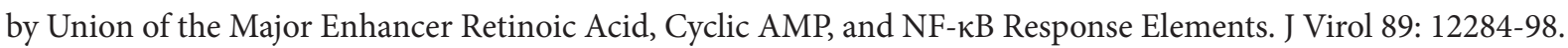

72. Li JM, Hossain MS, Southerland L, Waller EK (2013) Pharmacological inhibition of VIP signaling enhances antiviral immunity and improves survival in murine cytomegalovirus-infected allogeneic bone marrow transplant recipients. Blood 121: $2347-51$.

73. Yadav M, Goetzl EJ (2008) Vasoactive intestinal peptide-mediated Th17 differentiation: an expanding spectrum of vasoactive intestinal peptide effects in immunity and autoimmunity. Ann N Y Acad Sci 1144: 83-9.

74. Khodabakhsh P, Asgari Taei A, Mohseni M, Bahrami Zanjanbar D, Khalili H, et al. (2021) Vasoactive Peptides: Their Role in COVID-19 Pathogenesis and Potential Use as Biomarkers and Therapeutic Targets. Arch Med Res S0188-4409(21)00122-3.

75. Carniglia L, Ramírez D, Durand D, Saba J, Turati J, et al. (2017) Neuropeptides and Microglial Activation in Inflammation, Pain, and Neurodegenerative Diseases. Mediators Inflamm 2017: 5048616.

76. Delgado M, Varela N, Gonzalez-Rey E (2008) Vasoactive intestinal peptide protects against beta-amyloid-induced neurodegeneration by inhibiting microglia activation at multiple levels. Glia 56: 1091-103.

77. Mosley RL, Lu Y, Olson KE, Machhi J, Yan W, et al. (2019) A Synthetic Agonist to Vasoactive Intestinal Peptide Receptor-2 Induces Regulatory T Cell Neuroprotective Activities in Models of Parkinson's Disease. Front Cell Neurosci 13: 421.

78. Meregnani J, Clarençon D, Vivier M, Peinnequin A, Mouret C, et al. (2011) Anti-inflammatory effect of vagus nerve stimulation in a rat model of inflammatory bowel disease. Auton Neurosci 160: 82-9.

79. Borovikova LV, Ivanova S, Zhang M, Yang H, Botchkina GI, et al. (2000) Vagus nerve stimulation attenuates the systemic inflammatory response to endotoxin. Nature 405: 458-62.

80. Bonaz B, Sinniger V, Pellissier S (2016) Anti-inflammatory properties of the vagus nerve: potential therapeutic implications of vagus nerve stimulation. J Physiol 594: 5781-90.

81. Jin B, Singh R, Ha SE, Zogg H, Park PJ, et al. (2021) Pathophysiological mechanisms underlying gastrointestinal symptoms in patients with COVID-19. World J Gastroenterol 27: 2341-52. 
82. Bonaz B (2020) Parameters matter: modulating cytokines using nerve stimulation. Bioelectron Med 6: 12.

83. Tsaava T, Datta-Chaudhuri T, Addorisio ME, Masi EB, Silverman HA, et al. (2020) Specific vagus nerve stimulation parameters alter serum cytokine levels in the absence of inflammation. Bioelectron Med 6: 8.

84. Seth RK, Kimono D, Alhasson F, Sarkar S, Albadrani M, et al. (2018) Increased butyrate priming in the gut stalls microbiome associated-gastrointestinal inflammation and hepatic metabolic reprogramming in a mouse model of Gulf War Illness. Toxicol Appl Pharmacol 350: 64-77.

85. Pozzi G, Masselli E, Gobbi G, Mirandola P, Taborda-Barata L, et al. (2021) Hydrogen Sulfide Inhibits TMPRSS2 in Human Airway Epithelial Cells: Implications for SARS-CoV-2 Infection. Biomedicines 9: 1273.

86. Dai J, Teng X, Jin S, Wu Y (2021) The Antiviral Roles of Hydrogen Sulfide by Blocking the Interaction between SARS-CoV-2 and Its Potential Cell Surface Receptors. Oxid Med Cell Longev 2021: 7866992.

87. Giustarini D, Santucci A, Bartolini D, Galli F, Rossi R (2021) The age-dependent decline of the extracellular thiol-disulfide balance and its role in SARS-CoV-2 infection. Redox Biol 41: 101902.

88. Dominic P, Ahmad J, Bhandari R, Pardue S, Solorzano J, et al. (2021) Decreased availability of nitric oxide and hydrogen sulfide is a hallmark of COVID-19. Redox Biol 43: 101982.

89. Kalem AK, Kayaaslan B, Neselioglu S, Eser F, Hasanoglu İ, et al. (2021) A useful and sensitive marker in the prediction of COVID-19 and disease severity: Thiol. Free Radic Biol Med 166: 11-17.

90. Manček-Keber M, Hafner-Bratkovič I, Lainšček D, Benčina M, Govednik T, et al. (2021) Disruption of disulfides within RBD of SARS-CoV-2 spike protein prevents fusion and represents a target for viral entry inhibition by registered drugs. FASEB J 35: e21651.

91. Ali Qaba MAM, Saleem MK, Ali Qaba NK, Alani MA, Ahmed MM, et al. (2021) Assessment of Inhaled Hydrogen Sulfide in Suppressing Deterioration in Patients With COVID-19. Shock 56: 868-9.

92. Avdeev SN, Gaynitdinova VV, Merzhoeva ZM, Berikkhanov ZG (2021) N-acetylcysteine for the treatment of COVID-19 among hospitalized patients. J Infect 10: S0163-4453(21)00329-7.

93. Datzmann T, Merz T, McCook O, Szabo C, Radermacher P (2021) H2S as a Therapeutic Adjuvant Against COVID-19: Why and How? Shock 56: 865-67.

94. Yang G (2020) H2S as a potential defense against COVID-19? Am J Physiol Cell Physiol 319: C244-C249.

95. Evgen'ev MB, Frenkel A (2020) Possible application of H2S-producing compounds in therapy of coronavirus (COVID-19) infection and pneumonia. Cell Stress Chaperones 25: 713-5.

96. Twu WI, Lee JY, Kim H, Prasad V, Cerikan B, et al. (2021) Contribution of autophagy machinery factors to HCV and SARSCoV-2 replication organelle formation. Cell Rep 37: 110049.

97. Maity S, Saha A (2021) Therapeutic Potential of Exploiting Autophagy Cascade Against Coronavirus Infection. Front Microbiol 12: 675419. 
98. Shroff A, Nazarko TY (2021) The Molecular Interplay between Human Coronaviruses and Autophagy. Cells 10: 2022.

99. Yang L, Liu C, Zhao W, He C, Ding J, et al. (2018) Impaired Autophagy in Intestinal Epithelial Cells Alters Gut Microbiota and Host Immune Responses. Applied and environmental microbiology 84: e00880-18.

100. Messer JS (2017) The cellular autophagy/apoptosis checkpoint during inflammation. Cell Mol Life Sci 74: $1281-96$.

101. Zhou C, Li L, Li T, Sun L, Yin J, et al. (2020) SCFAs induce autophagy in intestinal epithelial cells and relieve colitis by stabilizing HIF-1a. J Mol Med (Berl) 98: 1189-202.

102. Zhang LN, Zhang XW, Li CQ, Guo J, Chen YP, et al. (2021) Vagal Nerve Stimulation Protects Against Cerebral IschemiaReperfusion Injury in Rats by Inhibiting Autophagy and Apoptosis. Neuropsychiatr Dis Treat 17:905-13.

103. St Leger AJ, Koelle DM, Kinchington PR, Verjans GMGM (2021) Local Immune Control of Latent Herpes Simplex Virus Type 1 in Ganglia of Mice and Man. Front Immunol 12: 723809.

104. Verjans GMGM, Hintzen RQ, van Dun JM, Poot A, Milikan JC, et al. (2007) Selective Retention of Herpes Simplex Virus Specific T Cells in Latently Infected Human Trigeminal Ganglia. Proc Natl Acad Sci USA 104: 3496-501.

105. Hanani M, Spray DC (2020) Emerging Importance of Satellite Glia in Nervous System Function and Dysfunction. Nat Rev Neurosci 21: 485-98.

106. van Velzen M, Jing L, Osterhaus AD, Sette A, Koelle DM, et al. (2013) Local CD4 and CD8 T-Cell Reactivity to HSV-1 Antigens Documents Broad Viral Protein Expression and Immune Competence in Latently Infected Human Trigeminal Ganglia. PloS Pathog 9: e1003547.

107. Ash RJ (1986) Butyrate-induced reversal of herpes simplex virus restriction in neuroblastoma cells. Virology 155: 584-92.

108. Clement C, Bhattacharjee PS, Kumar M, Foster TP, Thompson HW, et al. (2011) Upregulation of mouse genes in HSV-1 latent TG after butyrate treatment implicates the multiple roles of the LAT-ICP0 locus. Invest Ophthalmol Vis Sci 52: 1770-9.

109. Neumann DM, Bhattacharjee PS, Hill JM (2007) Sodium butyrate: a chemical inducer of in vivo reactivation of herpes simplex virus type 1 in the ocular mouse model. J Virol 81: 6106-10.

110. Rubio RM, Mohr I (2019) Inhibition of ULK1 and Beclin1 by an $\alpha$-herpesvirus Akt-like Ser/Thr kinase limits autophagy to stimulate virus replication. Proc Natl Acad Sci U S A 116: 26941-50.

111. Turan A, Grosche L, Krawczyk A, Mühl-Zürbes P, Drassner C, et al. (2019) Autophagic degradation of lamins facilitates the nuclear egress of herpes simplex virus type 1. J Cell Biol 218: 508-23.

112. Ahmad L, Mostowy S, Sancho-Shimizu V (2018) Autophagy-Virus Interplay: From Cell Biology to Human Disease. Front Cell Dev Biol 6: 155.

113. Lucinda N, Figueiredo MM, Pessoa NL, Santos BS, Lima GK, et al. (2017) Dendritic cells, macrophages, NK and CD8+ T lymphocytes play pivotal roles in controlling HSV-1 in the trigeminal ganglia by producing IL1-beta, iNOS and granzyme B. Virol J 14: 37 . 
114. Zolini GP, Lima GK, Lucinda N, Silva MA, Dias MF, et al. (2014) Defense against HSV-1 in a murine model is mediated by iNOS and orchestrated by the activation of TLR2 and TLR9 in trigeminal ganglia. J Neuroinflammation 11: 20.

115. Flowerdew SE, Wick D, Himmelein S, Horn AK, Sinicina I, et al. (2013) Characterization of neuronal populations in the human trigeminal ganglion and their association with latent herpes simplex virus-1 infection. PLoS One 8: e83603.

116. Wu B, Geng S, Bi Y, Liu H, Hu Y, et al. (2015) Herpes Simplex Virus 1 Suppresses the Function of Lung Dendritic Cells via Caveolin-1. Clin Vaccine Immunol 22: 883-95.

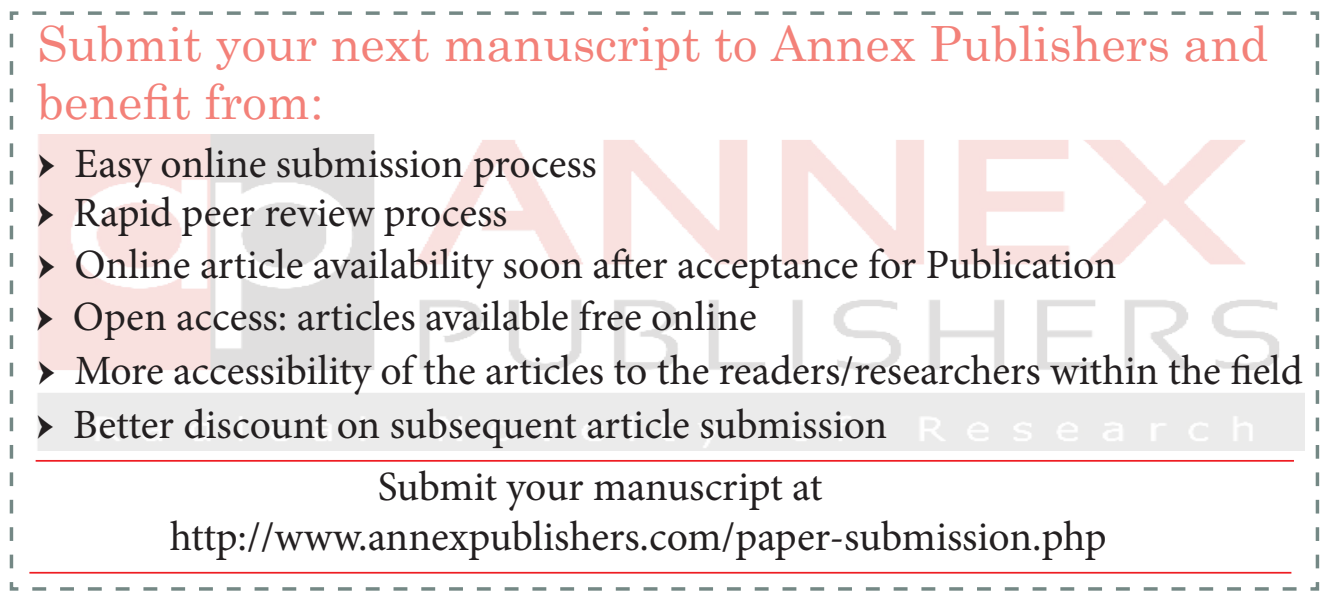

